\title{
Nanocrystalline Cellulose and Polyvinyl Alcohol Coating Application to Cardboard Packaging Papers and Investigation of the Effects on Paper Properties
}

\author{
Semiha YENIDOĞAN * \\ Marmara University School of Applied Sciences Department of Printing Technology, 34722, Istanbul, Turkey \\ crossref http://dx.doi.org/10.5755/j01.ms.26.3.21499
}

Received 22 August 2018; accepted 23 April 2019

\begin{abstract}
In the packaging sector of the printing industry, different coating applications are tried and investigated in order to increase the surface appearance and performance characteristics of paper and cardboard. The printability, water and ink absorption capacity, frictional resistance, light sensitivity of the visual graphical design that are going to be printed on the packaging papers are some of them. In this study, different types of cardboards that are used as a packaging material were chosen and coated with nanocrystalline cellulose (NCC)/PVA at different rates (\%). In order to determine effective and economical usage conditions, the coating solutions, at three different concentrations as 3 wt. $\%, 5$ wt. $\%, 7$ wt. $\%$, were prepared. The coating was applied on the test papers, which were at the same weights $\left(350 \mathrm{~g} / \mathrm{m}^{2}\right)$ and had different surface properties as matte glossy, bright glossy, American Bristol. NCC/PVA existence on the coated paper surface was confirmed with Fourier Transform Infrared Spectroscopy (ATR-FTIR). The impact of the coating, which was prepared at different concentrations, on the packaging materials was studied with respect to thickness, stiffness, water absorbability, contact angle and surface tension.

Keywords: nanocrystalline, nanocellulose, NCC, packaging paper, PVA, coating, cardboard coating.
\end{abstract}

\section{INTRODUCTION}

Packaging materials are widely used in various field, mainly cosmetics, food and beverages. These materials can be based on glass, aluminum, plastic and cellulose. The cellulose-based substrates are widely used in various industries such as packaging thanks to their high endurance, flexibility, low-cost and recyclability [1]. In comparison to other materials, the cellulose-based packaging materials have preferable superior properties in terms of their being lightweight, biodegradable, recyclable, eco-friendly and having lower cost [2-4].

In order to improve the performance properties of the papers, additives are added into the pulp or coated on the surfaces of paper as a thin film layer [5, 6]. However, as the surface coating materials, non-organic synthetic materials, such as kaolin, aluminum three hydroxide, zeolite, calcium carbonate, titanium oxide are used, along with different binders and chemicals as well as synthetic polymers, such as polyethylene, and materials like fluorocarbon. These materials are not recycled, ecofriendly and bio-degradable [7]. Due to these reasons, the use of eco-friendly and recyclable subtracts by the virtue of decreasing the synthetic coating agents possessed a great importance in terms of green chemistry and material science $[8-11]$.

Biopolymers have an advantage of being sustainable, renewable and biodegradable, therefore they also reduce the carbon footprint. Biopolymer materials have relatively stable pricing and these advantages are driving adoption of these natural products [12]. Nanocellulose materials' usage areas are gradually increasing because of their being green and ecological with respect to carbon footprint and

\footnotetext{
* Corresponding author. Tel.: +902163365770;

E-mail address: semihayavuz@marmara.edu.tr (S. Yenidoğan)
}

providing superior performance properties on the surface where they are applied $[13,14]$.

As well as the nanocrystalline cellulose is used in the composite materials because of their mechanical properties, they find a usage area in the paper sector with their biocompatibility, biodegradability and modular structure and their usage area is expanding $[15,16]$. Ridway et al. showed in their studies that nanocellulose improved the barrier properties of the papers [17]. Baht et al. claim that CNF/Clay blends improve the quality of printability [18]. Some of the recent nanomaterials in the papermaking and coating industry include nanocrystalline cellulose (NCC) [12]. The studies have demonstrated that these nano materials improve various important properties of coated paper, an example for the tensile strength and elastic modulus differences between the paper, polyvinyl alcohol (PVA) film, cellophane and TOCN film [19]. In the recent years, PVA is widely used as the carrier of the nano materials thanks to its fully biodegradable, non-toxic, biocompatible, water-soluble properties [20,21]. PVA is a linear and thermoplastic polymer. With its water-solubility and perfect chemical resistance, it is biodegradable and does not have any toxic impact on human body [22]. It was reported that PVA was successful in carrying carbon nanotube, chitin and cellulose nanofibers in nanofiller structures [23, 24].

In the recent years, it is endeavored to develop and improve the structure and surface properties of papers with the materials from renewable resources. NCC that can be easily found among this kind of materials draws great attention thanks to its renewability, biodegradability and good mechanical properties as well as the positive properties that it provides for the paper surface, in the recent years [25]. 
In this study, the test papers are covered with NCC/PVA at different percentage rates in order to study the physical, mechanical and printability properties. The water absorbability, tensile strength, surface energy, brightness values, decolorization process of the coated papers were analyzed.

\section{EXPERIMENTAL DETALS}

\subsection{Materials}

In this study, three different cardboard packaging paper, namely matte paper, glossy paper and American Bristol at the same weight $\left(350 \mathrm{~g} / \mathrm{m}^{2}\right)$ were used.

Table 1. Properties of test papers

\begin{tabular}{|l|l|c|c|c|}
\hline Properties & Test method & $\begin{array}{c}\text { Matte } \\
\text { paper }\end{array}$ & $\begin{array}{c}\text { Glossy } \\
\text { paper }\end{array}$ & $\begin{array}{c}\text { Bristol } \\
\text { paper }\end{array}$ \\
\hline Basis wt, g/m ${ }^{2}$ & ISO 536 & 350 & 350 & 350 \\
\hline Thickness, $\mu \mathrm{m}$ & ISO 534 & 0.30 & 0.26 & 0.49 \\
\hline Cobb $\left(\mathrm{g} / \mathrm{m}^{2} 60 \mathrm{~s}\right)$ & ISO 535 & 20 & 27 & 18 \\
\hline \multirow{2}{*}{ Stiffness, mNm } & ISO 2493 & 129 & 105 & 265 \\
\cline { 2 - 5 } & MD/CD & 85 & 87 & 137 \\
\hline Gloss, 75 & ISO 8254-1 & 33.7 & 65 & 46.4 \\
\hline Colour L ${ }^{*} \pm 0.8 \%$ & ISO 5631-2 & 100.18 & 99.89 & 100.58 \\
\hline $\mathrm{a}^{*} \pm 0.6$ & ISO 5631-2 & 0.11 & -0.03 & 0.17 \\
\hline $\mathrm{b}^{*} \pm 1.1$ & ISO 5631-2 & 0.37 & -0.09 & -0.52 \\
\hline
\end{tabular}

As the coating material Nanocrystalline Cellulose (NCC) material, provided from Nanolinter company, was used in dust form. The properties of NCC are given in Table 1 and their images in TEM device are shown in Fig. 1.

Table 2. NCC size and analysis properties

\begin{tabular}{|l|l|c|}
\hline Analysis name & Analysis output & $\begin{array}{c}\text { Nanocrystalline } \\
\text { Cellulose (NCC) }\end{array}$ \\
\hline TEM & Average grain size & $\begin{array}{c}\text { Length: } 223.90 \mathrm{~nm} \\
\text { Diameter: } 35.72 \mathrm{~nm}\end{array}$ \\
\hline DLS & Average grain size & $216.7 \mathrm{~nm}$ \\
\hline XRD & Crystallinity, $\%$ & $98.98 \%$ \\
\hline
\end{tabular}

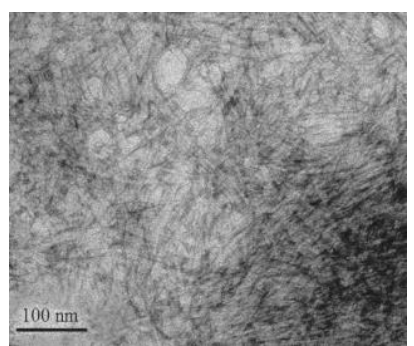



b
Fig. 1. TEM micrographs showing the morphology of NCC specimens produced from different hydrolysis conditions: $\mathrm{a}-\mathrm{NCC} 55 ; \mathrm{b}-\mathrm{NCC} 60$ [15]

As the nanocellulose carrier on the paper Polyvinyl Alcohol (PVA) (Mowiol 20-98) was chosen. PVA polymers' properties are given in Table 3 and Table 4.

Table 3. The properties of the PVA polymer, used in the study

\begin{tabular}{|c|c|c|c|}
\hline $\begin{array}{c}\text { PVA trade } \\
\text { name }\end{array}$ & $\begin{array}{c}\text { Abbreviated } \\
\text { name }\end{array}$ & $\begin{array}{c}\text { Average } \\
\mathrm{M}_{\mathrm{w}, \mathrm{Da}}\end{array}$ & $\begin{array}{c}\text { Nominal percent of } \\
\text { acetyl groups, \% }\end{array}$ \\
\hline Mowiol 20-98 & PVA-98 & 125000 & 2 \\
\hline
\end{tabular}

Table 4. Physical properties of polymer PVA

\begin{tabular}{|l|c|c|c|}
\hline Polymer & $\begin{array}{c}\text { Surface tension, } \\
\mathrm{mN} / \mathrm{m}\end{array}$ & $\begin{array}{c}\text { Viscosity, } \\
\times 10^{2} \mathrm{~Pa} \cdot \mathrm{s}\end{array}$ & $\begin{array}{c}\text { Conductivity, } \\
\mu \mathrm{S} / \mathrm{cm}\end{array}$ \\
\hline & $60.9 \pm 0.3$ & $14.1 \pm 0.1$ & $17.6 \pm 0.4$ \\
PVA-98 & $62.1 \pm 0.8$ & $17.2 \pm 0.1$ & $29.4 \pm 0.6$ \\
& $62.6 \pm 0.1$ & $17.8 \pm 0.2$ & $36.7 \pm 0.5$ \\
\hline
\end{tabular}

\subsection{Methods}

\subsubsection{Preparation of PVA/NCC suspension}

Polyvinyl alcohol solutions were prepared. PVA $5 \mathrm{~g}$ was dissolved in $80 \mathrm{~g}$ distilled water at $90{ }^{\circ} \mathrm{C}$ for $60 \mathrm{~min}$ under mechanical stirring. Then, the solutions were kept under stirring to reach room temperature NCC dispersions were added to obtain a result NCC content 3, 5, $7 \mathrm{wt}$ \% for coating, while keeping total PVA concentrations constant at $7 \mathrm{wt} . \%$. The obtained mixture was mixed at $80{ }^{\circ} \mathrm{C}$ for $120 \mathrm{~min}$ in a mechanical mixer. Then, it was cooled down in a refrigerator (12 hours). Afterwards, viscosity and surface tension were determined in room temperature with Brookfield DV-E Viscometer, and conductivity properties with WTW Cond. 3110 SET 3-2CA103. Prepared PVA/NCC mixture's physical properties are given in Table 5.

Table 5. Physical properties of PVA/NCC solutions

\begin{tabular}{|l|c|c|c|c|}
\hline Polymer & wt.\% & $\begin{array}{c}\text { Surface } \\
\text { tension, } \\
\mathrm{mN} / \mathrm{m}\end{array}$ & $\begin{array}{c}\text { Viscosity, } \\
\times 10^{2} \mathrm{~Pa} \cdot \mathrm{s}\end{array}$ & $\begin{array}{c}\text { Conductivity, } \\
\mu \mathrm{S} / \mathrm{cm}\end{array}$ \\
\hline PVA/NCC & 0 & $60.9 \pm 0.3$ & $14.1 \pm 0.1$ & $17.6 \pm 0.4$ \\
\hline PVA/NCC & 3 & $60.5 \pm 0.1$ & $14.5 \pm 0.1$ & $27.8 \pm 0.4$ \\
\hline PVA/NCC & 5 & $59.8 \pm 0.4$ & $15.1 \pm 0.1$ & $31.6 \pm 0.4$ \\
\hline PVA/NCC & 7 & $60.4 \pm 0.3$ & $15.2 \pm 0.1$ & $32.6 \pm 0.4$ \\
\hline
\end{tabular}

\subsubsection{Coating process}

The paperboards were coated (Laboratory Type Coating Machine-Atac Machine) using an automatically controlled Mayer rod number 2, pushing the suspension on top of the substrate with a Meyer rod at a fixed speed of 50 $\mathrm{mm} / \mathrm{s}$. This coating process was used to apply NCC to one side of the paperboards in single layer, and at three concentrations $(3,5$ and $7 \mathrm{wt} . \%)$. The samples were finally dried in standard conditions of $23{ }^{\circ} \mathrm{C}$ and $50 \%$ humidity for one day.

\subsubsection{Characterization}

In order to detect the existence of NCCs in Attenuated Total Reflectance-Fourier Transform Infrared Spectroscopy (ATR- FTIR) NCC/PVA coatings, was used Perkin Elmer Spectrum100 ATR-FTIR spectrophotometer.

\subsubsection{Thickness}

Thickness measurements of the control paper and coated test papers were made with a Sony brand micrometer with $0.01-20 \mu \mathrm{m}$ sensitivity, according to TAPPI 411 Standard.

\subsubsection{Taber stiffness}

Taber stiffness values of the coated papers were measured according to DIN 53121 Standard with an equipment (L\&W Stiffness Tester). 


\subsubsection{Cobb test}

Water absorption capacity, which represents the amount of absorbed water by unit area of paper in a defined period of time ( $60 \mathrm{~s}$ in this study), was evaluated by Cobb 60 index, according to TAPPI Standard T-441 om-98 method [26].

\subsubsection{Paper gloss}

Paper gloss of the coated papers was measured with BYK-Gardner GmbH glossmeter, and the results were determined, according to ISO 8252-1:2009 Standard [27]. Coated and uncoated test samples were exposed to thermal aging for lightfastness inside a closed cabin by using Solar box 1500 device under stable Xenon light for 48 hours, according to BS 4321-1969 Standard. After the lightfastness process, the gloss values of the papers were measured and the differences between the first measured values were calculated

\subsubsection{Surface energy}

Surface energy of the test papers were determined with the contact angle measurements, according to TAPPI T 458 Standard. Depending on time, the measurements were made with Pocket Goniometer Model PG-X, (FIBRO Systems AB, Sweden), program version 3.4. Surface "free" energy was calculated according to ASTM D5946 standard test method depending on the water contact angle.

\section{RESULTS}

\subsection{Fourier transform infrared spectroscopy (FTIR)}

In order to determine the characteristic vibrations of NCCs and PVA in NCC/ PVA coatings, the analyses were made with ATR-FTIR. The results are shown in Fig. 2.

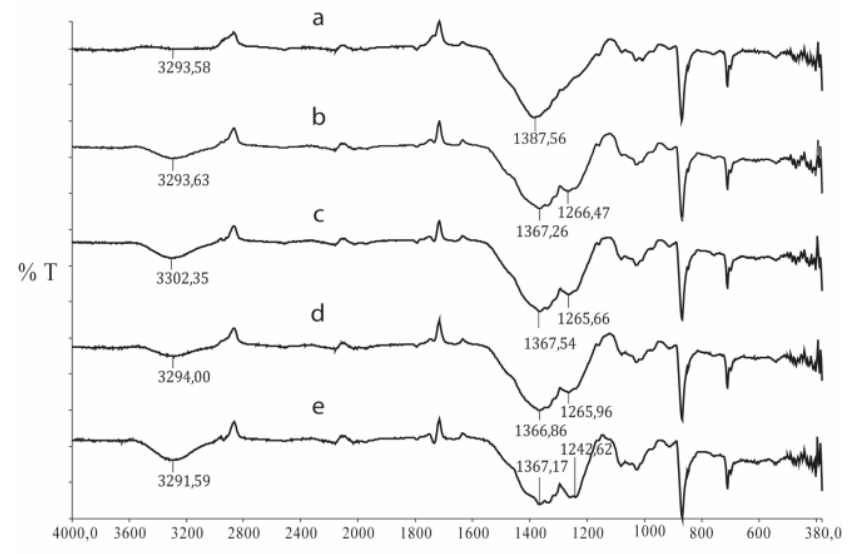

$\mathrm{cm}^{-1}$

Fig. 2. ATR-FTIR analysis: a-control paper; b-PVA coated paper; c-PVA + 3 wt. $\%$ NCC coated paper; d-PVA + 5 wt. $\%$ NCC coated paper; e-PVA + 7 wt. $\%$ NCC coated paper

In Fig. 2 an indicated a weak the characteristic $-\mathrm{OH}$ vibration of cellulose of paper $3293.58 \mathrm{~cm}^{-1}$, about $2900 \mathrm{~cm}^{-1}$ aliphatic $\mathrm{C}-\mathrm{H}$ stretch vibration of methylene, and aromatic $\mathrm{C}=\mathrm{C}$ stretching vibrations at $1387.56 \mathrm{~cm}^{-1}$, these peaks clearly explain the cellulosic paper chemical structures. Fig. 2 b, showed that the $\mathrm{O}-\mathrm{H}$ vibration is becoming more prominent because of PVA molecules. It has emerged a peak $1268.47 \mathrm{~cm}^{-1}$ because of $\mathrm{C}-\mathrm{O}$ of alcohol. Fig. $2 \mathrm{~b}$ is compatible with PVA sized paper's chemical structures. Fig. 2 c, d, e exhibited that NCC added PVA coated paper. It is clearly appeared that all paper and PVA peaks already at spectra but the intensity of $\mathrm{OH}$ vibration, $\mathrm{C}=\mathrm{C}$ stretching vibrations $\mathrm{C}-\mathrm{O}$ vibrations are increased. Also about $1260 \mathrm{~cm}^{-1}$ peak growth is from $\mathrm{NCC}$, which is related to the bending vibration of the $\mathrm{C}-\mathrm{H}$ and $\mathrm{C}-\mathrm{O}$ bonds in the polysaccharide aromatic rings. It is an expected result for these coatings [24].

\subsection{Thickness}

The thickness values of the papers, coated with three different concentrations of PVA/NCC mixture, are given in Fig. 3. There was a thickness change to a certain extent in the comparison which was made with the control paper samples on the papers coated with PVA after the coating process. The difference of PVA/NCC concentration did not affect the thickness values of the coated papers. The fact that the thickness values did not change shows that the coating had been stable and made at the same thickness, and these values increase the confidentiality of the results [1].

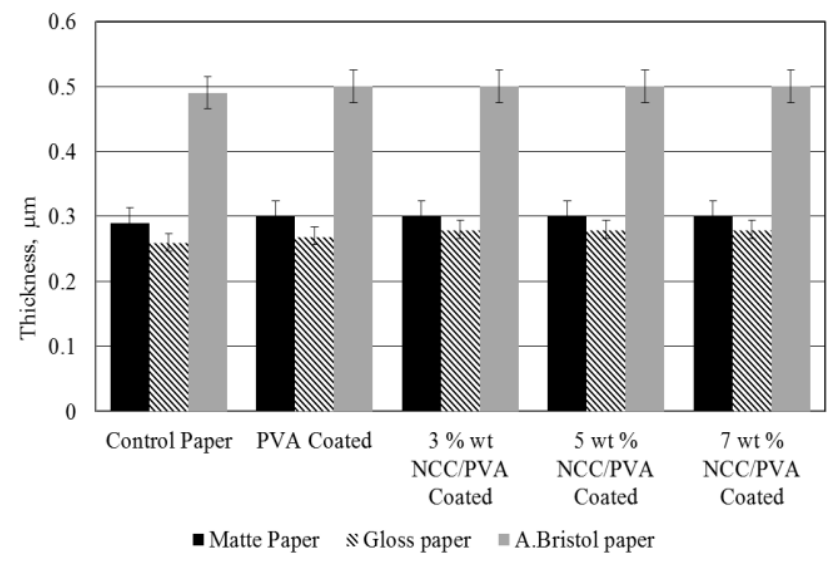

Fig. 3. Thickness properties of NCC/PVA coated papers

\subsection{Taber stiffness}

The Taber stiffness values of the test papers are showed in Table 6, and a general increase was observed in the values of the papers, coated with PVA/NCC concentration. When the stiffness values are taken into consideration, due to the cellulose structure of the paper, $(\mathrm{OH})$ groups of the molecules of the acetyl structure of the paper, which were between the nanocellulose molecules, and nanocellulose $-\mathrm{OH}$ molecules got into reaction and created $-\mathrm{H}$ bridges. Depending on the percentile increase of the nanocellulose, they caused an increase in the endurance values by providing the connection of the hydrogen bridges and alcohol groups of PVA on the $-\mathrm{OH}$ groups of the paper by the help of the hydrogen connections. Because cross linking occurs on the paper surface as the paper's hydroxyl groups and PVA's alcohol interact with one another, an increase was observed in the stiffness values. Due to the binding of NCC on the paper surface, the interaction between paper/nanocellulose, the 
creation of regular molecule chains and the orientation of the molecules between fibers, the stiffness values increased.

Table 6. Taber stiffness values of MD and CD PVA/NCC coated papers

\begin{tabular}{|l|c|c|c|}
\hline $\begin{array}{c}\text { Coated paper } \\
\text { properties }\end{array}$ & $\begin{array}{c}\text { Matte paper } \\
\text { (MD/CD) }\end{array}$ & $\begin{array}{c}\text { Glossy paper } \\
\text { (MD/CD) }\end{array}$ & $\begin{array}{c}\text { American } \\
\text { Bristol paper } \\
\text { (MD/CD) }\end{array}$ \\
\hline Control & $129 / 85$ & $105 / 87$ & $265 / 137$ \\
\hline PVA & $131 / 98$ & $105 / 88$ & $363 / 325$ \\
\hline PVA/NCC (3\%) & $137 / 64$ & $154 / 101$ & $366 / 285$ \\
\hline PVA/NCC (5\%) & $140 / 89$ & $132 / 103$ & $326 / 192$ \\
\hline PVA/NCC (7\%) & $123 / 93$ & $138 / 87$ & $320 / 293$ \\
\hline
\end{tabular}

MD/CD rates are shown, in Table 6. These increase rates in percentages according to different papers types, an increase of $2.3 \%$ was observed when matte coated papers were coated with PVA. While matte coated papers were coated with NCC/PVA mixtures, the best result of Taber stiffness value was $5 \%$ with NCC addition and $8.5 \%$ in MD values, and $-15.2 \%$ in CD values with PVA coating. When $3 \%$ NCC was added to the Taber stiffness values of Glossy coated papers, $46 \%$ increase was observed in MD values, and $17.9 \%$ improvement in $\mathrm{CD}$ values with $5 \%$ NCC. In the Taber stiffness values of American Bristol papers, an increase was observed in MD/CD 0 values with NCC addition, while an increase was provided at the rates of $38.1 / 137.2 \%$ in the Taber stiffness values of the PVA coated American Bristol papers [28].

\subsection{Cobb index (water absorption capacity)}

The papers' water absorption capacity depends on their properties and coating materials' structures. Fig. 4 shows $3 \mathrm{wt} \%$ nanocrysaline cellulose coating, applied on matte coated paper and American Bristol papers, was the best result. And it is $5 \mathrm{wt} . \%$ nanocellulose coating in gloss coated paper. In all of these three paper types $7 \mathrm{wt} \%$ coating results were negative. However, it is related to the increase in the hydrophobic properties of the coated papers, caused by nanocellulose at 7 wt.\%. With the PVA coating on the paper, the increase was observed in the values of the cobb index. It is caused by the $-\mathrm{H}$ bridges that PVA creates on the paper surface because of being easily solvable [29].

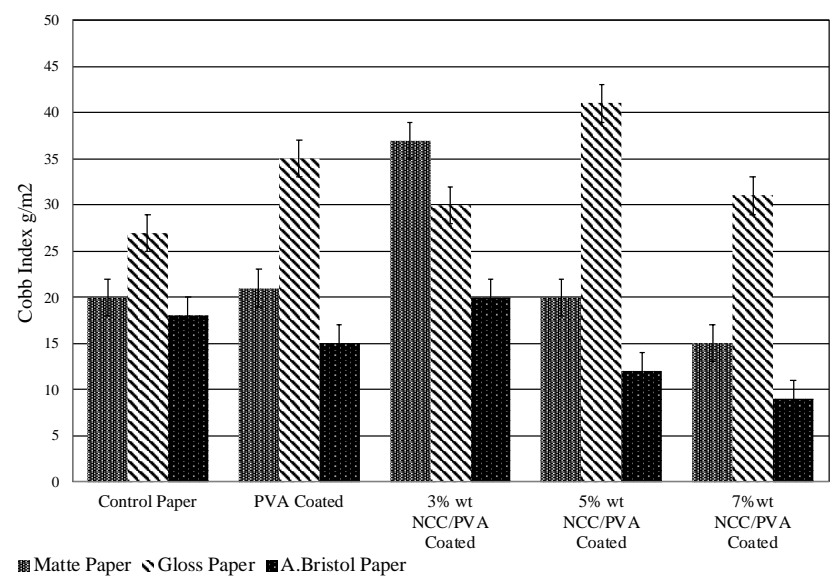

Fig. 4. Cobb index of NCC/PVA coated papers

\subsection{Paper gloss}

When the test papers were examined in terms of the brightness values, the brightness values of all of the papers increased, compared to the unprocessed control papers. When the values of the papers before and after lightfastness are taken into consideration, it was observed that the heat treatment decreased the brightness values at a certain amount. When the matte paper gloss value changes are examined, it is seen that $3 \mathrm{wt} \%$ PVA/NCC concentration is the most ideal rate in terms of brightness (Fig. 5).

When gloss paper gloss value changes are examined, it is seen in the PVA coated result. When it is taken into consideration in terms of PVA/NCC concentration, 3 wt.\% should be preferred in case that more brightness is wanted when 3 wt.\% and 5 wt.\% rates are convenient (Fig. 6).

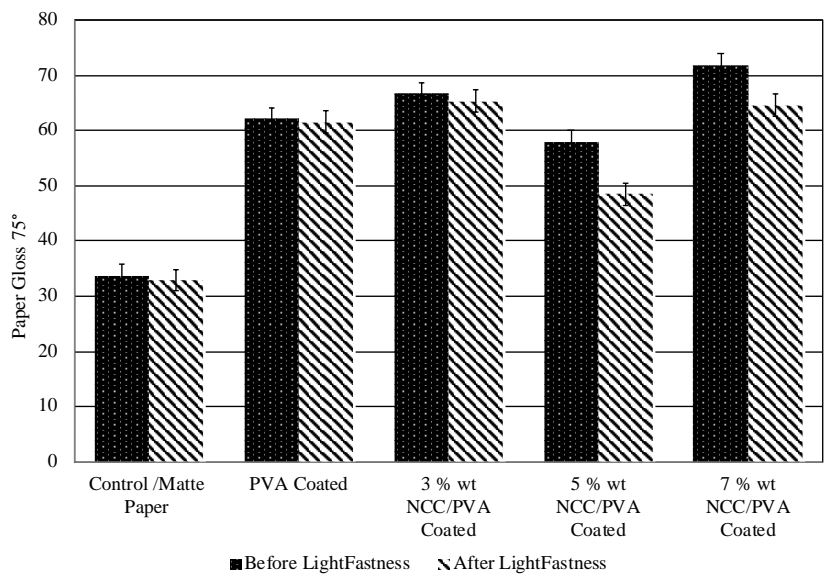

Fig. 5. Matte paper gloss values changes

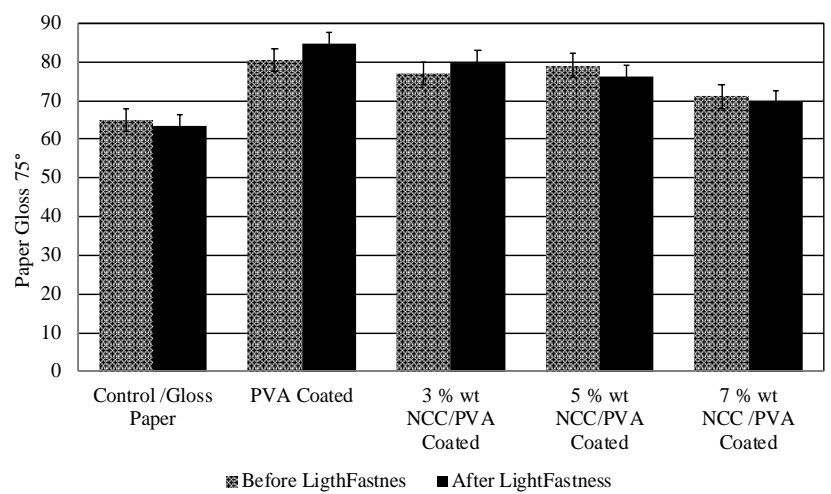

Fig. 6. Gloss paper gloss values changes

When American Bristol Paper gloss value changes was examined, it was the most balanced paper type in terms of before and after light sensitivity. After PVA coating the brightness value increased and then 3 wt.\% PVA/NCC concentration gave the most ideal concentration by decreasing a little bit (Fig. 7).

\subsection{Surface energy}

In general, materials with higher values bond better because good wet-out occurs. Wet-out is an industry term to describe the flow of a liquid over the destination's surface. Good wet-out ensures maximum contact and helps achieve strong bonding [30]. 


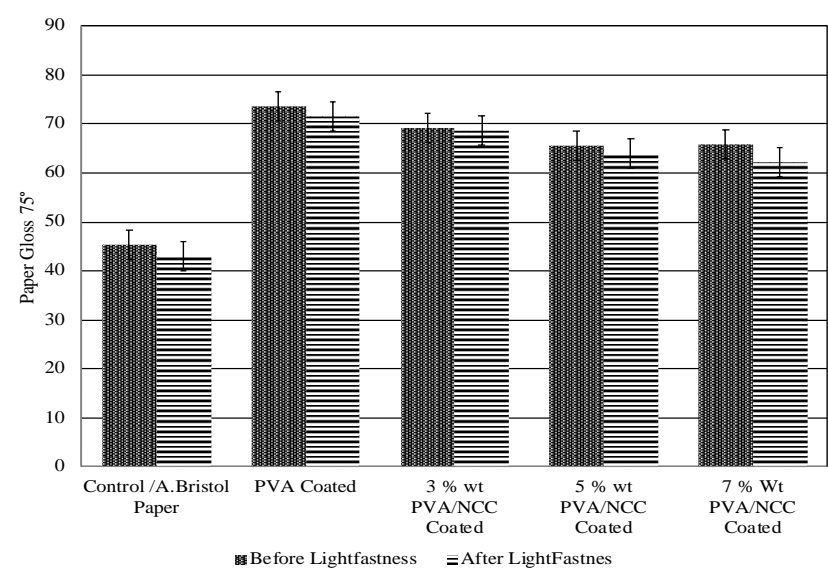

Fig. 7. American Bristol paper gloss values changes

The results of the contact angle measurement of the PVA/NCC coating, applied in different concentrations of 3, 5, 7 wt.\% on the American Bristol, matte and gloss coated test papers, were evaluated in comparison with the samples of the control paper, it was found that when their concentrations increased, the contact angle decreased and the absorption properties of the surfaces increased. It can be said that the NCC in the mixture increases the water absorption and decreases the contact angle of all paper types.

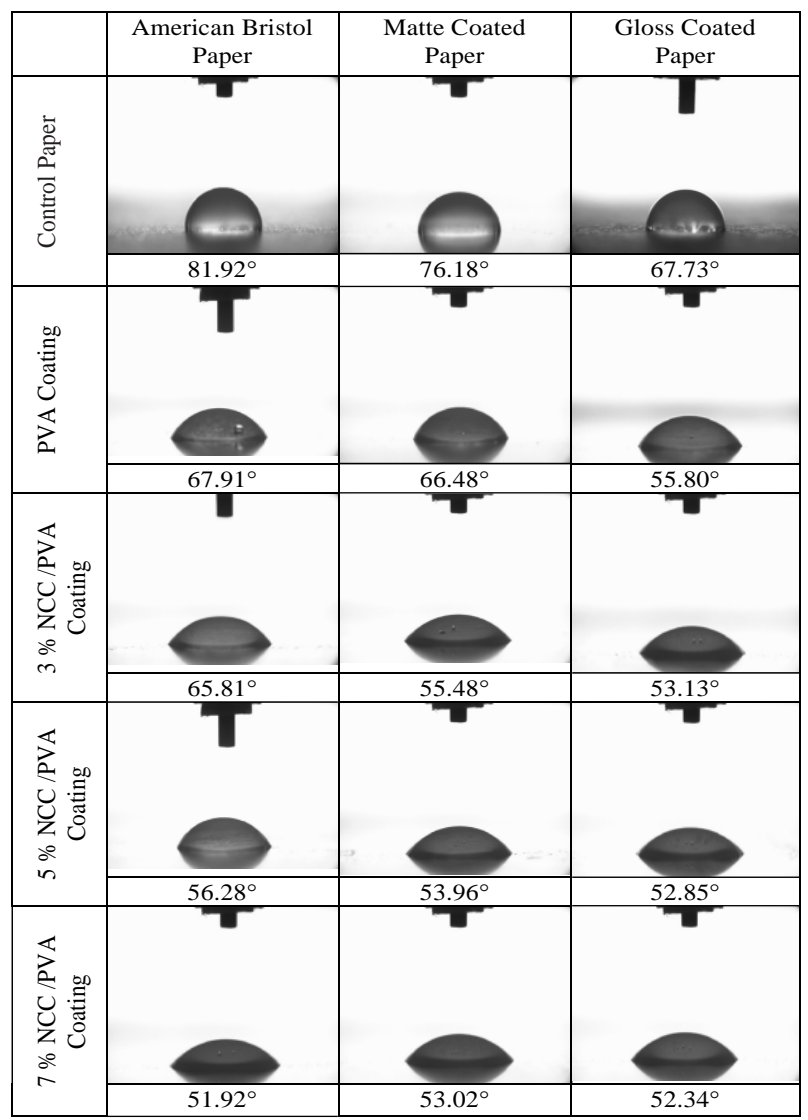

Fig. 8. Test paper contact angle

The contact angle decreased in only the American Bristol and gloss papers, coated with PVA, at $17 \%$ rate and at $12 \%$ at the matte coated paper. As the PVA/NCC concentration increased 3, 5 and $7 \mathrm{wt} . \%$, the contact angle continued to decrease and wettability increased in all of the papers. The decrease occurred in the American Bristol paper with the highest different at $36 \%$ rate, reached the lowest value with $51,92^{\circ}$ of contact angle, and it became the lowest value in terms of wettability (Fig. 8).

\section{CONCLUSIONS}

In this study, NCC/PVA surface coating applications were applied on the cardboard packaging papers, with different weights and properties, at different concentrations. After coating, the performances of the packaging papers' thickness, stiffness, cobb index, surface contact angle and surface tension properties were evaluated. According to this:

1. There was not any change in the thickness of the packaging paper after coating. It was found that the coating on the paper performed an even and uniform distribution.

2. In the stiffness and Cobb Index values, an increase occurred with the impact of $-\mathrm{OH}$ links that occurred in the molecules of NCC/PVA surface coatings.

3. There was a general increase in the gloss values of the packaging papers and the most ideal paper gloss properties were achieved with the NCC/PVA coating at 3 wt. \% concentration.

4. While an increase was observed in the liquid absorption values depending on the concentration increase of the NCC/PVA surface coatings, a decrease was observed in the values of the contact angles.

5. After the application of the NCC/PVA coatings at different concentrations on different packaging papers, it was seen that they made a positive contribution to the performance properties on the basis of the examined properties.

\section{REFERENCES}

1. Afra, E., Mohammadnejad, S., Saraeyan, A. Cellulose Nanofibrils as Coating Material and its Effects on Paper Properties Progress in Organic Coating 101 2016: pp. $455-460$. https://doi.org/10.1016/j.porgcoat.2016.09.018

2. Hansen, N.M.L., Plackett, D. Sustainable Films and Coatings from Hemicelluloses Biomacromolecules 9 (6) 2008: pp. $1493-505$. https://doi.org/10.1021/bm800053z

3. Rodionova, G., Lenes, M., Eriksen, G. Surface Chemical Modification of Microfibrillated Cellulose: Improvement of Barrier Properties for Packaging Applications Cellulose 18 (1) 2011: pp. $127-134$. https://doi.org/10.1007/s10570-010-9474-y.

4. Bastioli, C. Global Status of the Production of Biobased Packaging Materials Starch 53 (8) 2001: pp. 351-355.

5. Ozcan, A., Zelzele, Ö.B. The Effect of Binder Type on the Physical Properties of Coated Paper Mus Alparslan University Journal of Science 5 (1) 2017: pp. 399-404.

6. Aydemir, C. A Study on the Printability Properties of Alkali-sized Recycled Papers Science and Engineering of Composite Materials 23 (5) 2016: pp. 565-571.

7. Gómez, E.F., Michel, F.C. Biodegradability of Conventional and Bio-Based Plastics and Natural Fiber Composites During Composting, Anaerobic Digestion and Long-Term Soil Incubation Polymer Degradation and Stability 98 (12) 2013: pp. 2583-2591. 
https://doi.org/10.1016/j.polymdegradstab.2013.09.018

8. Kettle, J., Lmminmaki, T., Gane, P. A Review of Modified Surface for High-Speed Inkjet Coating Surface \& Coating Technology 204 (12-13) 2010: pp. 2103-2109. http://dx.doi.org/10.1016/j.surfcoat.2009.10.035

9. Reis, A.B., Yoshida, C.M.P., Reis, A.P.C., Franco, T.T. Application of Chitosan Emulsion as a Coating on Kraft Paper Polymer International 60 (6) 2011: pp. 963-969.

10. Afra, E., Yousefi, H., Hadilam, M.M., Nishino, T. Comparative Effect of Mechanical Beating and Nanofibrillation of Cellulose on Paper Properties Made from Bagasse and Softwood Pulps Carbohydrate Polymers 97 (2) 2013: pp. $725-730$. https://doi.org/10.1016/j.carbpol.2013.05.032

11. Rezayati-Charani, P., Dehghani-Firouzabadi, M., Afra, E., Blademo, A., Naderi, A., Lindström, T. Production of Microfibrillated Cellulose from Unbleached Kraft Pulp of Kenaf and Scotch Pine and Its Effect on the Properties of Hardwood Kraft: Microfibrillated Cellulose Paper Cellulose 20 (5) 2013: pp. 2559-2567.

https://doi.org/10.1007/s10570-013-9998-z

12. Altay, B.N., Bloembergen, S., Aydemir, C., Karademir, A., Fleming, P.D. Use of Nanoparticle Binders for Paper Coatings Journal of Graphic Engineering and Design 8 (1) 2017: pp. 39-43. http://doi.org/10.24867/JGED-2017-1-039

13. Taipale, T., Österberg, M., Nykänen, A., Ruokolainen, J., Laine, J. Effect of Micro Fibrillated Cellulose and Fines on The Drainage of Kraft Pulp Suspension and Paper Strength Cellulose 17 (5) 2010: pp.1005-1020. https://doi.org/10.1007/s10570-010-9431-9

14. Klemm, D., Kramer, F., Moritz, S., Lindström, T., Ankerfors, M., Gray, D., Dorris, A. Nanocelluloses: A New Family of Nature-Based Materials Angewante. Chemie International Edition 50 (24) 2011: pp. $5438-5466$. https://doi.org/10.1002/anie.201001273

15. Chang, C.P., Wang, I.C., Hung, K.J., Perng, Y.S. Preparation and Characterization of Nanocrystalline Cellulose by Acid Hydrolysis of Cotton Linter Taiwan Journal for Science 25 (3) 2010: pp. 231 - 244.

16. Sheikhi, A., Van de Ven, T.G. Colloidal Starch and Cellulose Nanocrystals Unite to Improve the Mechanical Properties of Paper: from Enhanced Coatings to Reinforced Nanocomposites ACS Applied Nano Materials 1(4) 2018: pp. $1841-1852$.

17. Ridgway, C.J., Gane, P.A.C. Constructing NFC-Pigment Composite Surface Treatment for Enhanced Paper Stiffness and Surface Properties Cellulose $19(2)$ 2011: pp. $547-560$. https://doi.org/10.1007/s10570-011-9634-8

18. Bhat, A.H., Khan, I., Usmani, M.A., Rather, J.A. Bioplastics and Bionanocomposites Based on Nanoclays and Other Nanofillers. In: Jawaid M., Qaiss A., Bouhfid R.(eds)
Nanoclay Reinforced Polymer Composites. Engineering Materials. Springer, Singapore. 2016: pp. 115-139.

19. Fukuzumi, H., Saito, T., Isogai, A. Influence of TEMPOOxidized Cellulose Nanofibril Length on Film Properties Carbohydrate Polymers 93 (1) 2013: pp. 172 - 177. https://doi.org/10.1016/j.carbpol.2012.04.069

20. Nair, S.S., Zhu, J.Y., Deng, Y., Ragauskas, A.J. High Performance Green Barriers Based on Nanocellulose Sustainable Chemical Processes 2 (23) 2014: pp. 7. https://doi.org/10.1186/s40508-014-0023-0

21. Incani, V., Danumah, C., Boluk, Y. Nanocomposites of Nanocrystalline Cellulose for Enzyme Immobilization Cellulose 20 (1) 2013: pp. 191-200. https://doi.org/10.1007/s10570-012-9805-2

22. Kaboorani, A., Riedl, B., Blanchet, P., Fellin, M., Hosseinaei, O., Wang, S. Nanocrystalline Cellulose (NCC): A Renewable Nano-Material for Polyvinyl Acetate (PVA) Adhesive European Polymer Journal 48 (11) 2012: pp. $1829-1837$.

23. Jeong, J.S., Moon, J.S., Jeon, S.Y., Park, J.H., Alegaonkar, P.S., Yoo, J.B. Mechanical Properties of Electrospun PVA/Mwnts Composite Nanofibers Thin Solid Films 515 (12) 2007: pp. 5136-5141.

24. Peresin, M.S., Habibi, Y., Zoppe, J.O., Pawlak, J.J., Rojas, O.J. Nanofiber Composites of Polyvinyl Alcohol and Cellulose Nanocrystals: Manufacture and Characterization Biomacromolecules 11 (3) 2010: pp. 674-681. https://doi.org/10.1021/bm901254n

25. Shen, J., Fatehi, P., Ni, Y. Biopolymers for Surface Engineering Of Paper-Based Products Cellulose 21 (5) 2014: pp. $3145-3160$. https://doi.org/10.1007/s10570-014-0380-6.

26. TAPPI Standard T-441 Om-98, Water Absorptiveness of Sized (Non-Bibulos) Paper, Paperboard, and Corrugated Fibreboard (Cobb Test) (2009).

27. Aydemir, C., Yenidoğan, S., Karademir, A., Arman, E. Effects of Color Mixing Components on Offset Ink and Printing Process Materials and Manufacturing Processes 32 (11) 2017: pp. 1310-1315. https://doi.org/10.1080/10426914.2017.1279323

28. Bordenave, N., Grelier, S., Pichavant, F., Coma, V. Water and Moisture S. Susceptibility of Chitosan and Paper-Based Materials: Structure-Property Relationships Journal of Agricultural and Food Chemistry 5(23) 2007: pp. 9479-9488. https://doi.org/10.1021/jf070595i

29. Kirwan, M.J. Paper and Paperboard Packaging Technology, ed. By Kirwan MJ. Blackwell Publishing, Oxford, 2007: pp. 39-41. https://doi.org/10.1002/9780470995877.ch1

30. Rhim, J., Lee, J., Hong, S. Increase in Water Resistance of Paperboard by Coating with Poly (Lactide) Packaging Technology \& Science 20 (6) 2007: pp. 393-402. https://doi.org/10.1002/pts.767 